\title{
Suitability evaluation of groundwater from the Skhira coastal aquifer of east-central Tunisia for use as drinking water
}

\author{
Fadoua Hamzaoui-Azaza ${ }^{1,}{ }^{,}$, Rihem Trabelsi ${ }^{2}$, and Rachida Bouhlila $^{2}$ \\ ${ }^{1}$ Sedimentary environments Oil systems and Reservoir characterization Laboratory, University of \\ Tunis El Manar, UR11 ES15, 2092 Tunis, Tunisia \\ ${ }^{2}$ Modeling in Hydraulic and Environment Laboratory, University of Tunis El Manar, Tunisia
}

\begin{abstract}
The Skhira coastal aquifer is located in east central Tunisia. It is already affected by the intrusion of saline water phenomena. This study evaluated the suitability of aquifer groundwater various using data on chemical and physical data from 31 wells for the decade from 2000-10. Salinity increases in the direction of flow and exceeds $10 \mathrm{~g} / \mathrm{L}$ in the northeast region. Groundwater composition is controlled primarily by the concentrations of sodium, chlorides and sulphates. The majority of the groundwater samples are not potable.
\end{abstract}

\section{Introduction}

Climate constraints, population growth, and economic and social transformations are the reasons for a increasing demand for water in Tunisia. This ever-increasing demand has exhausted water resources in Tunisia and many regions in the world [1]. In addition to the scarcity of water resources consumption of contaminated water is unsafe. Determination of groundwater composition is important for the evaluation of its suitability for domestic and irrigation uses. This study evaluated the quality of groundwater of the Skhira aquifer in the semi-arid region of eastern Tunisia for drinking water suitability.

\section{Study area}

The Skhira aquifer comprises an area of $514 \mathrm{~km}^{2}$. It is bounded on the north by the Bir Ali Ouadrane aquifer, on the west by the aquifer of Sebkhat Naoual, on the south by the limit of the aquifer of Gabès, and on the East by the Mediterranean Sea (Fig. 1).

The study area is characterized by an arid Mediterranean climate with a long dry season. Rainfall is irregular with an annual average that varies between $200-250 \mathrm{~mm} / \mathrm{yr}$. The annual cumulative evaporation in the Tunisian southeast sector is between 1400-2000 mm/yr [3], producing a negative water balance in this region. This water deficit is estimated between $1200-1300 \mathrm{~mm} / \mathrm{yr}$ [3]. Moreover, the annual water balance in the region of Gabes is negative and equal to $1420 \mathrm{~mm}[4]$.

\footnotetext{
*Corresponding author: fadoua_fst@yahoo.fr
} 


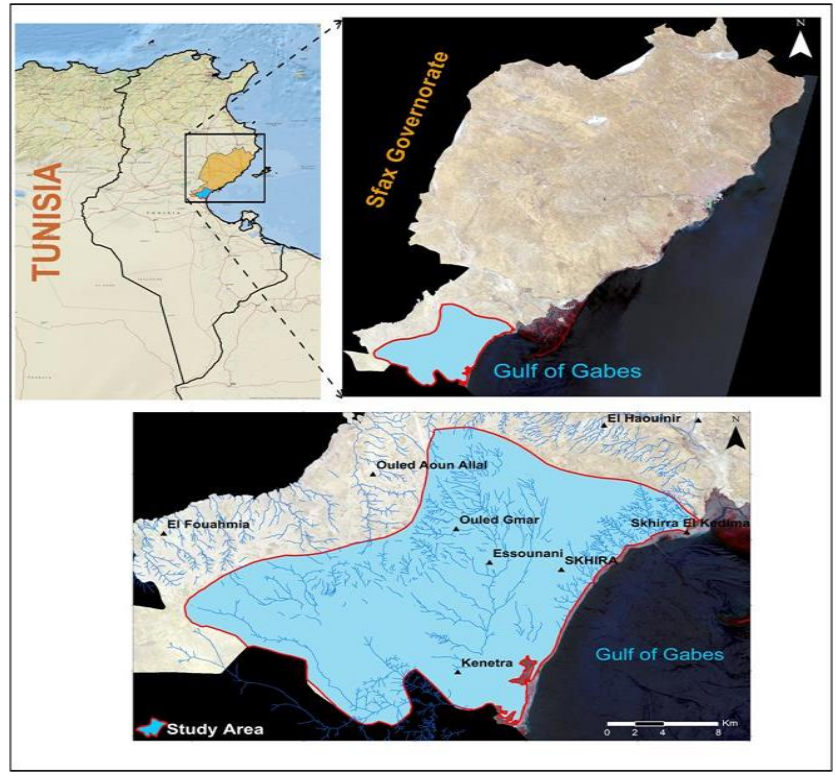

Fig. 1. Location maps of the study area.

The geological series across the Skhira region are of Quaternary age. The only Cretaceous-age outcrops are located in the western and southwestern limits of the area and constitute respectively the structures of Zemlet el Beida ,Zbara el Kbira, and Zbara EsSrhira. Major faults have three main orientations: N-S, NE-SW and NW-SE [5]. The main source of water supply is the infiltration of meteoric water, especially from river infiltration during its NW-SE flow. The subsurface aquifer is formed by four levels consisting of fine sands, separated by semi-permeable clay-sandy levels, allowing communication between different aquifer units. The main discharge for this aquifer is the Mediterranean Sea. Flow of the aquifer is from the north to southeast, from an upstream elevation $+42 \mathrm{~m}$ to $+6 \mathrm{~m}$ downstream. Piezometric maps established during the years from 1981-2002 indicate a decrease in the piezometric surface, which is due to the increasing withdrawal of groundwater (Fig. 2).

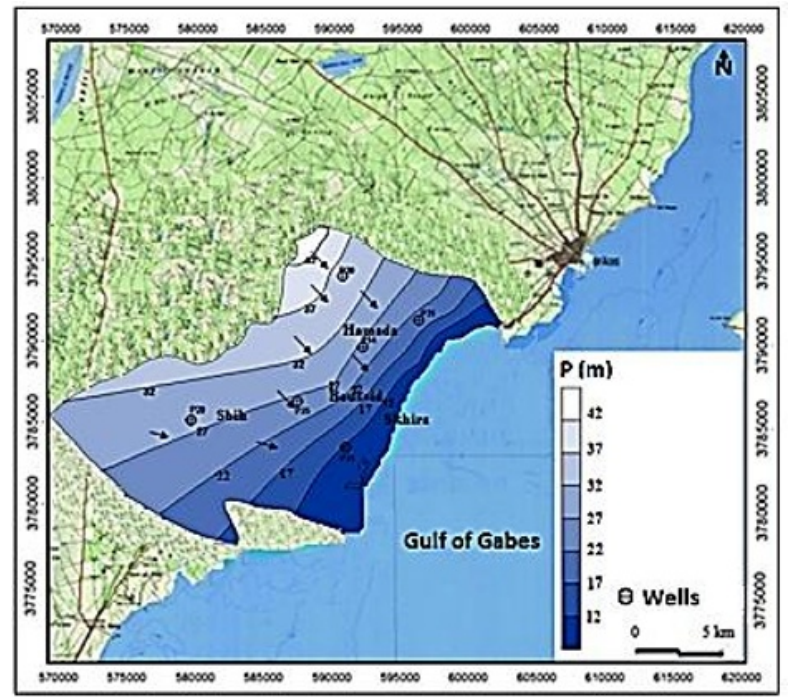

Fig. 2. Piezometric map of the aquifer. 
Groundwater exploitation was nearly constant from 1970 to 1974 on the order of $5 \times 10^{6} \mathrm{~m}^{3} / \mathrm{yr}$. An overall increase of exploitation to $>8.3 \mathrm{~mm}^{3} / \mathrm{yr}$ occurred from 1981 to 2010 , following the successive installation of several new wells into the Skhira aquifer, which is the principal source for water supply of the region.

\section{Methodology}

This hydrochemical study of the groundwater of the Skhira aquifer is based mainly on the $\mathrm{pH}$, TDS, and major element concentrations measured in sampling campaigns carried out by the Regional Direction of Agriculture and Water Resources of Sfax during the period from 2000-2010 that sampled 31 water points (Fig. 3). The main objective of this geochemical approach is to determine groundwater suitability for drinking.

In fact, sampling of water conditions the relevance of the analysis. Thus, we must respect certain instructions to ensure the credibility of the analysis results, in particular the Representativeness, bottling, packaging and preservation of the sample. All Water was only taken from boreholes that were pumped for a significant amount of time to get a representative sample. Temperature, $\mathrm{pH}$ and conductivity were measured on field. Chloride was determined by standard $\mathrm{AgNO}_{3}$ titration. Bicarbonates were determined by titration with $\mathrm{H}_{2} \mathrm{SO}_{4}[1,6]$. Sulfate concentration was measured by the gravimeter method using $\mathrm{BaCl} 2$, sodium and potassium were measured by flame photometry, and calcium and magnesium ions were determined titrimetrically using standard ethylenediaminetetraacetic acid $[1,6]$. TDS was measured by evaporating a pre-filtered sample to dryness.

The validation of the results of the chemical analyzes was carried out by the verification of their percent charge balance errors $(\% \mathrm{CBE})$. The latter was calculated according to the following equation $[1,7]$ :

$$
\text { Error }(\%)=|S e ́ q(+)-S e ́ q(-)| /(S e q(+)+S e q(-)) \times 100
$$

where $\mathrm{S}$ éq $(+)$ : sum of cation equivalents and $\mathrm{S}$ eq (-): sum of equivalents of anions. Generally, the ion-balance error does not exceed $\pm 6 \%$.

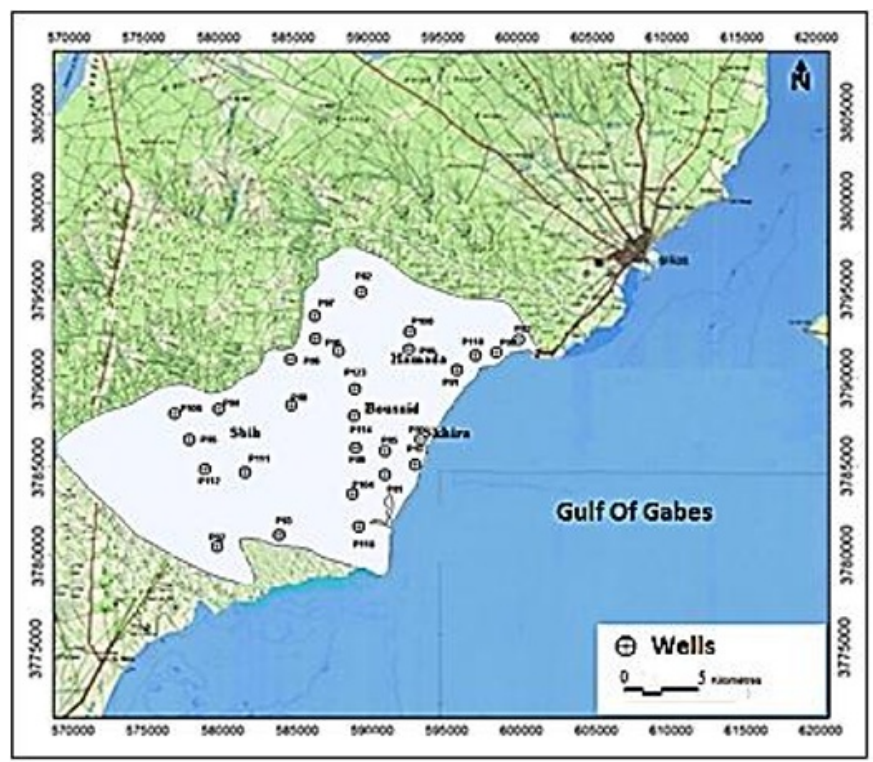

Fig. 3. Location of wells into the Skhira aquifer. 


\section{Results and Discussion}

The quality standards for drinking water have been specified by the World Health Organization (WHO). Some countries adopted their own standards and others choose those set by the WHO, while Tunisia has set national standards (NT.09.14) for drinking water.

Groundwater of the Skhira aquifer had $\mathrm{pH}$ values in 2010 that varied between 6.9 to 7.9 (Fig. 4). The groundwater of the Skhira aquifer has a salinity that at $2000 \mathrm{mg} / \mathrm{L}$ exceeds Tunisian standard. Concentrations of $\mathrm{Ca}$ and $\mathrm{Mg}$ (Fig. 4) in Skhira aquifer groundwater do not conform to the standards set by NT-09-14, while the K concentrations are within the standards. The $\mathrm{Cl}$ content of a majority of waters exceeded the limit values for drinking water set by NT.09.14 and sulphate concentrations for all wells are significantly higher than the maximum permissible concentration of $400 \mathrm{mg} / \mathrm{L}$.

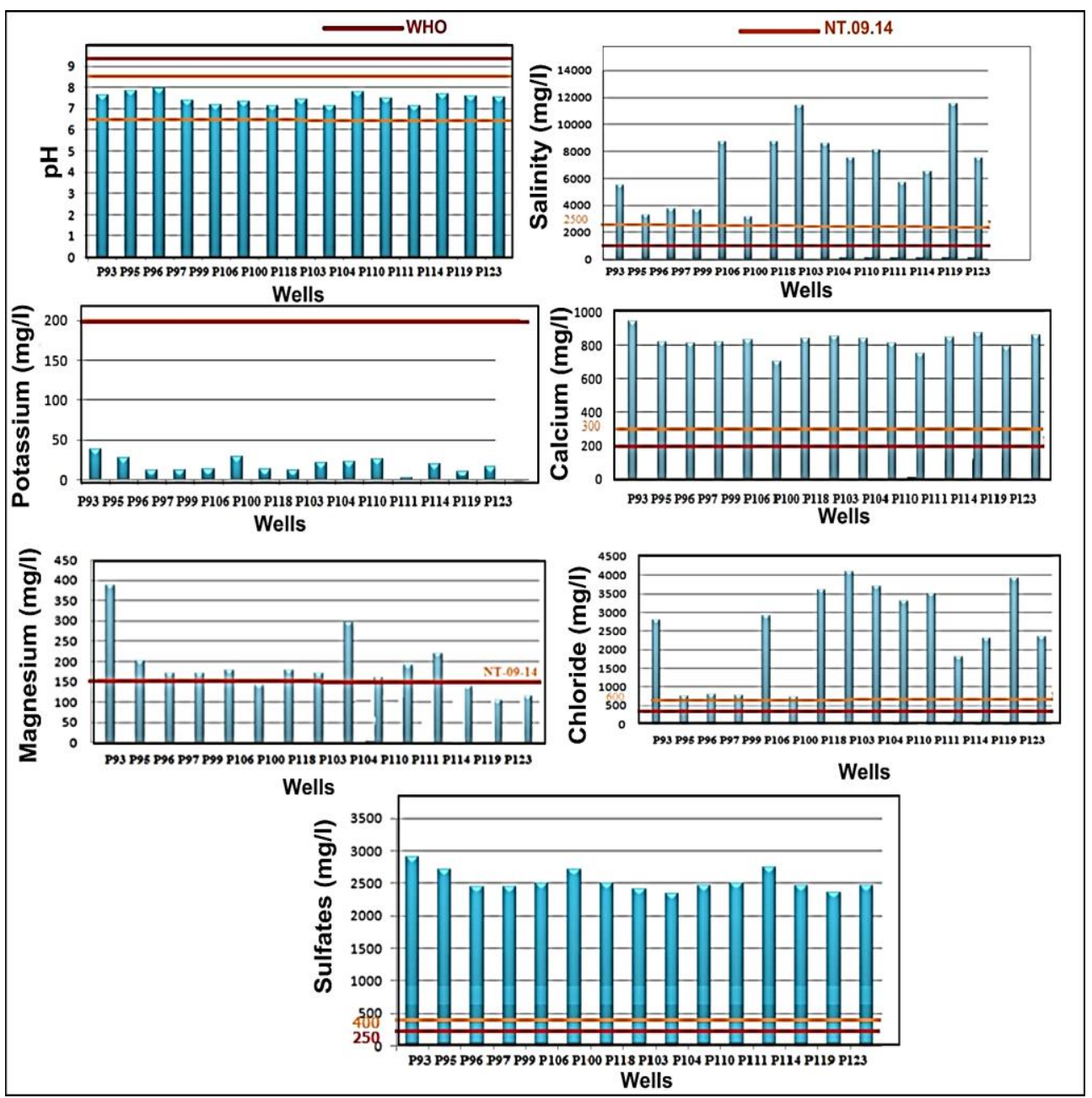

Fig. 4. Comparison of $\mathrm{pH}$, salinity and major ion concentration in Skhira aquifer groundwater with WHO standards and Tunisian norms NT 09-14.

\section{Conclusions}

Evaluation and sustainability considerations of groundwater resources are of extreme importance in arid and semi-arid regions. It is not only due to the basic needs for human 
existence, but also as a vital input for all development activities [8]. The groundwater quality of Skhira aquifer has been evaluated for its suitability with respect to irrigational and domestic works. The sample analysis reveals that all groundwater samples exceeded the permissible limits of WHO and Tunisian standards (NT.09.14) for drinking water.

\section{References}

1. F. Hamzaoui-Azaza, et al., Environ Monit Assess, 174, 283-298 (2011)

2. F. Hamzaoui-Azaza, et al., Chem Speciatio Bioavail, 25/3, 165-178 (2013)

3. S. Maghrebi, PhD thesis, Univ Paris Sud - Orsay, (1995)

4. J.P. Bettoux, Oceanol Acta, 2, 157-163. (1979)

5. R. Trabelsi, Master Report, ENIT (2015)

6. J. Rodier, L'analyse de l'eau, Ed Dunod Paris (1996)

7. R.A. Freeze, J.A. Cherry, Groundwater. Engle wood Cliffs: Prentice-Hall (1979)

8. M. Ameur, et al, Desalin.Water Treat, 57 (2016) 